Then came "scleral reinforcement," implanting slings around the eyeball to stop it elongating. These early blunderbuss approaches were soon abandoned, yet both extraction and reinforcement have made a cautious comeback in the past year or two.

Then, with the rapid deployment of corneal grafting techniques after the second world war, came "keratomileusis" (quick freezing of an excised corneal layer, grinding it to a predetermined shape, and suturing it back in position) and "keratophakia" (inserting a piece of appropriately tailored donor cornea over or within the cornea, or inlaying an equivalent piece of acrylic). All of these methods have their advocates today, especially when there is a gross anisometropia (which can thus be neutralised) along with intolerance of contact lenses.

The latest, and most popular, operation for correcting myopia is radial keratotomy, consisting of eight or more deep cuts into the corneal substance radiating around a central clear area of $2 \frac{1}{2}$ to $4 \mathrm{~mm}$ diameter, with the aim of so weakening the stroma of the cornea that its periphery becomes more curved and its central area flatter. This operation was devised by Sato et al in 1953, ${ }^{7}$ and interest rather lapsed until dramatic reports of its benefit came from Russia, ${ }^{8}$ in which a profusion of accounts retailed by our lay press sought to compensate for a lack of any detailed assessment. More controlled reports (especially from America) have now established, however, that (at any rate, in the short term) there is a genuine reduction of the myopia by about $4 \mathrm{D} .{ }^{9}$ The main reservation is the risk of permanent damage to the corneal endothelium, which has a strictly limited population of cells that gradually die and cannot be replaced. Once these have been reduced to about half irreversible oedema of the cornea follows. Since the cuts may well penetrate the endothelium even in the most expert hands, any direct injury will then be aggravated by further cuts buckling the cornea in an already softened eye.

Clearly radial keratotomy can benefit low myopes (though not without ultimate risk) but such persons are rarely among the patients who are desperate for a "cure." Low myopes are usually content to keep their "driving glasses" in the car and manage well enough without glasses indoors (if necessary, like the ancient Greeks, half closing their eyes for a momentary distant view), secure in the knowledge that by middle age they will have reason to be grateful for a myopic eye, which will allow them to read blithely without spectacles till they die.

Myopes are indeed rather an élite; they have a relatively high IQ, they preponderate in the higher educational and income levels ${ }^{10}$ and in the higher Indian castes; they are also more numerous in art schools, ${ }^{11}$ where they generally prefer to paint with their myopia uncorrected or undercorrected. Is some of this all round success due to a myopia which led them to study harder and read more, rather than the other way round? Youthful enthusiasts for the healing knife might well have second thoughts.

\section{PATRICK TREVOR-Roper}

Consultant Ophthalmic Surgeon

London NW1 $4 \mathrm{LJ}$

Zhong R-X, Shi R-R, Huang L-X, et al. Prevention and treatment of youth myopia by binocular near fogging. Chin Med f 1983;96:457-62. Ruben $\mathrm{M}$, quoted in Hodges C. View of eyes today. BMA News Review 1983 Jan:14-6.

Bates WH. The cure of imperfect sight by treatment without glasses. New York: 1920.

' Huxley A. The art of seeing. New York: Harper, 1942.

5 Fukala. Operative Behandlung des Hochstgradigen Myopie durch A phakie. V Graefes Archiv Fur Archiv fur Opthalmologie 1890;36:230-44.

${ }^{6}$ Müller L. Hat der lenticonus Seinen grund in einer anomalie der hinteren linsenfläch? Klin Monatsbl Augenheilk 1894;32:178-94.
${ }^{7}$ Sato $\mathrm{T}$, Akiyama $\mathrm{K}$, Shibata $\mathrm{H}$. A new surgical approach to myopia. Am 7 Ophthalmol 1953;36:823-9.

${ }^{8}$ Fyodorov SN, Durner VV. Operation of dosaged dissection of corneal circular ligament in cases of myopia of mild degree. Ann Ophthalmol $1979 ; 11: 1885-90$.

9 Steele ADMcG, Buckley RJ, Sherrard ES. Early experiences with radial keratotomy. Trans Ophthalmol Soc UK 1982;102:35-41.

10 Sperduto RD, Seigel D, Roberts J, Rowland M. Prevalence of myopia in the United States. Arch Ophthalmol 1983;101:405-7.

11 Patry A. Welchen Einfluss hat die Refraction auf des werk des Malers. Klin Monatsbl Augenheilk 1917;58:597.

\section{Poliomyelitis vaccine precautions}

Eradication of poliomyelitis is already technically feasible by the use of either oral attenuated poliovaccine or intramuscular inactivated poliovaccine, though various economic, organisational, and cultural problems militate against this being achieved by the year 2000 . An historic international symposium on poliomyelitis control attended by both Drs Salk and Sabin held in Washington, DC, earlier this year ${ }^{1}$ discussed improvements in vaccines, including development of a much more potent intramuscular inactivated poliovaccine which may be combined with diphtheria, tetanus, and pertussis antigens and give good protection after only two injections, thus fulfilling the objectives of earlier workers. ${ }^{2}$ Current research may lead to the identification and production of specific immunogenic polypeptides, and other studies may find a way to delete from polioviruses the virulence genes so that future live vaccines may be completely free of even the tiniest risk of causing paralysis. ${ }^{3}$

Although the Sabin type oral attenuated poliovaccine is still one of the safest vaccines in use, ${ }^{4}$ even rare adverse effects become of concern once the natural disease has been brought under such good control as in Britian. Contraindications should be scupulously observed, particularly the need to avoid giving live vaccines such as oral attenuated poliovaccine to patients with natural or artificial immunodepression. Non-living intramuscular inactivated poliovaccine may be given to these immunodeficient people. The progeny of oral attenuated poliovaccine excreted by someone given the vaccine may revert slightly towards virulence, putting some non-immune contacts at risk: these include not only unvaccinated immunodeficient contacts but also normal adult close contacts, particularly unimmunised parents of vaccinated children, since the risk of paralysis complicating poliovirus infection is much higher in adults than in children. Unvaccinated parents should, therefore, be given the opportunity of correcting their susceptibility by receiving oral attenuated poliovaccine straight from the bottle at the same time as their child.

Pregnancy is generally considered a contraindication to any live vaccine and, though oral attenuated poliovaccine has not been found to cause damage in pregnancy, intramuscular inactivated poliovaccine is to be preferred if immunisation is essential. In the United States, intramuscular inactivated poliovaccine is recommended for the primary immunisation of any adult.

What about such factors as recent tonsillectomy, vigorous exercise, and "provocation" by injections of bacterial vaccines or other irritants-all of which were found to increase the risk and severity of paralysis by poliovirus in the prevaccine 
era? These factors have not figured prominently in analyses of vaccine associated paralysis, and the familiar routine administration of both oral attenuated poliovaccine and triple diphtheria, tetanus, and pertussis vaccine to children has not proved dangerous. In particular, the pertussis vaccine has not emerged as an agent provocateur for poliomyelitis associated with oral attenuated poliovaccine.

Any case of acute paralysis which might possibly be due to poliovirus, whether after vaccination or otherwise, should be immediately investigated by testing stool specimens for the presence of virus. Virulent polioviruses still abound in the world and may be imported into countries such as Britain to exploit any gaps in individual or herd immunity. Occasional cases of paralytic poliomyelitis still occur in Britain in unvaccinated children and adults with or without recent travel abroad, and we must be on guard against any complacent, premature belief that this infection need no longer be considered in differential diagnosis.

Virological tests can distinguish vaccine derived from "wild" strains of poliovirus more accurately nowadays, and they can also identify the occasional cases of poliomyelitis due to those other enteroviruses against which poliomyelitis vaccines cannot be expected to protect. Continuing surveillance by both virological and epidemiological techniques is essential for satisfactory and sustained control. Meanwhile, better vaccines are on the way, though the present vaccines are so good that any improvements will be impossibly difficult to show in field trials.

\section{NORMAN R GRIST}

Professor of Infectious Diseases,

Regional Virus Laboratory,

Ruchill Hospital,

Glasgow G20 9NB

${ }^{1}$ International symposium on poliomyelitis control, Washington, 1983. Rev Infect Dis (in press).

${ }^{2}$ Dick G. Combined vaccines. Can $\mathcal{F}$ Public Health 1966;57:435-46.

${ }^{3}$ Grist NR. Safety of poliomyelitis vaccines. Br Med f 1983;286:917.

4 WHO Consultative Group. The relation between acute persisting spinal paralysis and poliomyelitis vaccine-results of a ten-year enquiry. Bull WHO 1982;60:231-42.

\section{Prostacyclin-powerful, yes: but is it useful?}

To realise why we cannot answer the question asked in the title we need to take the story of the discovery of prostacyclin back to its unlikely origins in the work of two gynaecologists in $1930 .{ }^{1}$ We must follow the trail through a period of quiescence and neglect until we reach an unprecedented explosion of research in the 1970s, culminating in the award of the 1982 Nobel prizes for medicine and the marketing of prostacyclin in 1983 (by then, and over 2000 scientific papers too late, renamed epoprostenol).

In 1930 the instillation of fresh human semen into the uterus was found to cause powerful muscular contraction or relaxation. ${ }^{1}$ The activity resided in a lipid soluble acidic fraction, which could be further subdivided by ether and phosphate buffer extraction. Because the source of the active agents was thought to be the prostate they were named "prostaglandins," and because of the way in which ether and phosphate are spelt in Swedish the subfractions were labelled prostaglandin $\mathrm{E}$ and prostaglandin $\mathrm{F}$ respectively. They were regarded as a curiosity or an irrelevance, though the structural studies carried out by Bergström and his colleagues ${ }^{2} 3$ began to show that the biological activities were due to a family of unsaturated hydroxy acids with an entirely novel shape which resembled a hairpin bent around a five membered ring.

The existence of a large family of prostaglandins provided the explanation of the confusing and conflicting pharmacological results which hitherto had been obtained by testing body fluids and tissue extracts, and in the 1960s increasingly refined synthetic techniques made it possible to study individual prostaglandins instead of indeterminate mixtures of variable and shifting composition.

Individual pure prostaglandins were soon shown to have profound effects on tissues other than smooth muscle. The first link with the thrombotic story came in 1967, when prostaglandin $\mathrm{E}_{1}$ was shown to be the most powerful inhibitor of platelet aggregation so far discovered ${ }^{4}{ }^{5}$ and to be capable of stopping injured animal arteries from forming platelet thrombi when it was infused intravenously. ${ }^{5}$ Attempts to infuse it into man confirmed that platelet inhibition could be producedbut at a price in respect of vasoactive and gut side effects, ${ }^{6}$ which we shall meet again as our story unfolds.

By now, the recognition of the universal distribution of prostaglandins and their powerful biological effects was blowing away the fog of neglect which had hidden them from general view for four decades. Soon they were found to play a crucial part in many disturbances of body function such as inflammation. Vane ${ }^{7}$ showed that the therapeutic effects of salicylates and aspirin like drugs were due to their ability to prevent the synthesis of proinflammatory prostaglandins. This aspirin effect was due to inhibition of the cyclo-oxygenase enzymic step which transforms membrane arachidonic acid into the cyclic endoperoxides prostaglandin $G_{2}$ and p:ostaglandin $\mathrm{H}_{2}$. The hunt was then on for the identity of derivatives of these endoperoxides which were mediating the inflammatory response. Samuelsson and his colleagues ${ }^{8}$ provided the answer when they showed that platelets and white cells could use the cyclic endoperoxides to generate a highly active substance which they named thromboxane. This was found to have a short half life; the initial, short lived compound was named thromboxane $A_{2}$ and its stable derivative thromboxane $B_{2}$. Thromboxane $A_{2}$ was found to have intense vasoconstrictor, bronchoconstrictor, and cytolytic activity as well as being a very powerful platelet aggregator.

The final step in the chain that led to the marketing of prostacyclin (alias epoprostenol) came in 1976 when the Wellcome group ${ }^{9}$ found that vessel walls could use the same arachidonate derived endoperoxides, prostaglandin $G_{2}$ and prostaglandin $\mathrm{H}_{2}$, to generate an unstable material which had diametrically opposing properties to thromboxane $A_{2}$; this artery derived substance (which they named prostaglandin $\mathrm{X}$ but was subsequently rechristened prostaglandin $\mathrm{I}_{2}$ and prostacyclin) was a vasodilator, a bronchodilator, a cytoprotective, and a very powerful inhibitor of platelet aggregation. Indeed the concentration of prostaglandin $\mathrm{E}_{1}$, previously regarded as the most powerful ratural inhibitor of aggregation, which inhibited adenosine diphosphate aggregation by half was 21 $\mathrm{ng} 1$ while for prostacyclin it was only $0.4 \mathrm{ng} 1 .^{10}$

The complementary nature of thromboxane $\mathrm{A}_{2}$ and prostacyclin led to increasing speculation about their Yin and Yang functions in the economy of the body in health and disease. Might the blood be maintained in its normal fluid state only because "good" prostacyclin from vessel walls kept "bad" 